\title{
Effects of Administration of Carbamazepine and/or Phenytoin on Serum Biochemical Parameters in Wistar Rats.
}

\author{
Hadiza Aliyu $^{*}$, Joseph O. Ayo ${ }^{2}$, Suleiman F. Ambali ${ }^{1,3}$, Muftau Shittu ${ }^{1}$, \\ Chinedu Orieje ${ }^{1}$, Richard Ejeh ${ }^{1}$. \\ 1 Department of Veterinary Pharmacology and Toxicology, Faculty of Veterinary Medicine, Ahmadu Bello \\ University, Zaria, Nigeria \\ 2 Department of Veterinary Physiology, Faculty of Veterinary Medicine, Ahmadu Bello University, Zaria, \\ Nigeria \\ 3 Department of Veterinary Physiology and Pharmacology, Faculty of Veterinary Medicine, University of \\ Ilorin, Ilorin, Nigeria
}

\begin{abstract}
This study was conducted to evaluate the serum biochemical alterations following the administration of carbamazepine (CBZ) and/or phenytoin (PHE) in Wistar rats. Forty male adult Wistar rats weighing between 144 and $300 \mathrm{~g}$ were used for the experiment. They were divided into four (4) groups of 10 animals each. Rats in groups II, III and IV were given CBZ (20 mg/kg), PHE (100 mg/kg) and CBZ+PHE (20 and $100 \mathrm{mg} / \mathrm{kg}$ separately), respectively. Rats in group I were given distilled water at $2 \mathrm{ml} / \mathrm{kg}$ and served as untreated control. All treatments were administered orally by gavage. The regimens were given once daily for a period of eight weeks. At the end of the experiment, the rats were sacrificed and serum samples were obtained for the analysis of total proteins, albumin, globulin, urea, $\mathrm{Na}^{+}, \mathrm{K}^{+}, \mathrm{Cl}$, and activities of alanine aminotransferase (ALT), aspartate aminotransferase (AST), alkaline phosphatase (ALP) and lactate dehydrogenase (LDH). There was an increase in the concentration of $\mathrm{Na}^{+}(P<0.0001)$ concentration, albumin $(P<0.01)$ and a decrease in urea (CBZ and PHE groups) $(P<0.05)$, globulin $(P<0.05)$ and $K^{+}$(CBZ group) $(P<0.05)$ concentrations. The activities of ALT in the CBZ and CBZ+PHE groups and that of AST activity in the PHE group increased significantly $(P<0.05)$.

In conclusion, administration of CBZ and/or PHE induced significant alterations in serum biochemical parameters in Wistar rats. It is recommended that serum biochemical parameters should be strictly monitored and regularly evaluated in individuals treated with CBZ and/or PHE in order to alleviate or prevent some of these changes.
\end{abstract}

KEYWORDS

Albumin

Globulin

Electrolytes

Liver enzymes

Proteins

\section{Introduction}

Phenytoin (PHE), carbamazepine (CBZ) and phenobarbitone are the first-line antiepileptic drugs. Despite the availability of newer antiepileptic drugs, the first line drugs are commonly used because of their efficacy and low cost $[1,6]$. Rational polypharmacy of antiepileptic drugs is one of the treatment strategies for refractory epilepsy [26] For example; a combination of carbamazepine and valproate has been tested in mice in different ratios and was more beneficial at a ratio of 1:20 in mice than when each of the drugs was administered [26]. Epilepsy encompasses a group of syndromes that vary in its associated pathology and seizure types [17]. It may be associated with enhanced excitatory amino acid transmission, impaired inhibitory transmission or abnormal electrical properties of the affected cells [21]. The characteristic event in epilepsy is the seizure, which is associated with the episodic high frequency discharge of impulses by a group of neurones [21]. CBZ is an anticonvulsant used to treat epilepsy and mood disorders [3]. It is administered alone or in combination with other medications to treat certain types of seizures in patients with epilepsy [18]. Its main function is reduction of sustained repetitive firing in neurones by blocking voltage-gated sodium channels [14]. CBZ exerts its therapeutic effects through the inhibition of brain neuronal activities, used for the treatment of seizure disorders and trigeminal and other neuralgias [23]. Severe liver failure is much less common in individuals using the drug, but has been reported with CBZ therapy [27], implicated in the aetiology of immunological abnormalities with decreased IgG, IgA and IgM [9]. PHE is one of the classical antiepileptic drugs [12]. It acts by blocking sodium channels and inhibiting persistent sodium currents in neurones, thus inhibiting neuronal firing in the brain [5]. PHE is an anticonvulsant used to control grand mal and psychomotor seizures. It has also been shown to protect 
axons within white matter, subjected to anoxia [8]. PHE exerts a transient inhibitory effect on antidiuretic hormone (ADH), and it may increase sodium ion concentration [13]. Diphenylhydantoin, a PHE derivative was reported to cause a more frequent and higher increase in alanine aminotransferase (ALT), aspartate aminotransferase (AST) and alkaline phosphatase (ALP) than CBZ [24].

However, there is paucity of information on the effects of some of the drug combinations on serum biochemical parameters.

The aim of the study was to evaluate the effects of administration of CBZ and/or PHE on serum biochemical parameters in adult male Wistar rats

\section{Materials And Methods}

Animals

Forty adult male Wistar rats weighing between 144 and $300 \mathrm{~g}$ were used for the experiment. The animals were obtained from the Animal House of the Department of Veterinary Physiology and Pharmacology, Ahmadu Bello University, Zaria, and were housed in rat cages. The animals were fed pellets made from grower's mash (Grand Cereals, Jos, Nigeria), maize bran and groundnut cake in the ratio 4:2:1, with wheat flour serving as binder, and water was provided ad libitum. The animals were allowed to adapt to their new environment for a period of two weeks before the commencement of the experiment.

Anticonvulsant Drugs

The anticonvulsant drugs used in this study were CBZ tablets (Hovid Bhd, Malaysia) at $20 \mathrm{mg} / \mathrm{kg}$ [20] and PHE capsules (BIOMEDICINE Belgium) at $100 \mathrm{mg} / \mathrm{kg}$ [29].

\section{Experimental Protocols}

The rats were divided at random into four groups of 10 animals each. Animals in groups II, III and IV were given CBZ (20 mg/kg), PHE (100 mg/kg) and CBZ+PHE (20 and $100 \mathrm{mg} / \mathrm{kg}$ separately), dissolved in distilled water, respectively. Rats in group I were given distilled water at $2 \mathrm{ml} / \mathrm{kg}$ and served as the untreated control. All treatments were administered orally by gavage once daily for a period of eight weeks. Thereafter, the rats were sacrificed and blood was collected for evaluation of biochemical parameters.

\section{Serum Biochemical Examination}

Blood sample $(5 \mathrm{ml})$ was collected from each rat into test tubes and incubated for 60 minutes, centrifuged at $1,000 \mathrm{~g}$ for 10 minutes to obtain serum. Thereafter, serum was collected from each test tube into clean sample tubes, which were subsequently used for the evaluation of serum biochemical parameters. The activities of alanine aminotransferase (ALT), aspartate amino transferase (AST), alkaline phosphatase (ALP) including the concentrations of electrolytes $\left(\mathrm{Na}^{+}, \mathrm{K}^{+}\right.$and $\left.\mathrm{Cl}^{-}\right)$and urea also total serum proteins, serum albumin and Serum globulin concentrations were all determined using autoanalyzer (Bayer Clinical Chemistry Analyzer, Germany). Lactate dehydrogenase (LDH) activity was estimated based on the principle that LDH catalysed the conversion of pyruvate to lactate; nicotinamide adenine dehydrogenase (NADH) was oxidized to nicotinamide adenine dinucleotide in the process. The rate of decrease in NADH was directly proportional to the LDH activity. The LDH activity was estimated using a kit (Optimized Standard Kit; Roche/Hitachi), and the absorbance was read using a spectrophotometer [Shimadzu Double-beam Digital Atomic Absorption/Flame Spectrophotometer Model AA-650 (202-37200), Shimadzu Corporation, Tokyo, Japan].

The research was carried out following the Animal Research Committee of the Ahmadu Bello University, Zaria, Nigeria and National Institutes of Health Guide for Care and Use of Laboratory Animals (Publication number 85-23), revised 1985.

\section{Statistical Analysis}

Values obtained were expressed as mean \pm SEM and subjected to statistical analysis using one-way analysis of variance (ANOVA), followed by Tukey's post-hoc test. The programme used for the analysis was GraphPad Prism, Version 4.0 for Windows from GraphPad Software, San Diego, Carlifornia, USA (www.graphpad.com). Values of $\mathrm{P}<0.05$ were considered significant.

\section{Effect of Treatments on Serum Electrolyte Concentrations \\ IV. Results \\ Effect of Treatments on Sodium ion Concentration}

There were significant $(\mathrm{P}<0.001)$ increases in $\mathrm{Na}^{+}$concentrations in the CBZ, PHE and CBZ+PHE groups, when respectively compared to that of the control group. Change in $\mathrm{Na}^{+}$concentration in the CBZ group was not significantly $(\mathrm{P}>0.05)$ different from that of PHE or CBZ+PHE group. The difference in $\mathrm{Na}^{+}$concentration in the PHE group compared to that of the CBZ+PHE group was not significant $(\mathrm{P}>0.05)$ (Figure 1.0). 


\section{Effect of Treatments on Potassium ion Concentration}

The changes in $\mathrm{K}^{+}$concentration in the PHE group when compared to those of the control and the CBZ+PHE groups were not significantly different. There was a significant $(\mathrm{P}<0.05)$ decrease in $\mathrm{K}^{+}$ concentration in the $\mathrm{CBZ}$ and $\mathrm{CBZ}+\mathrm{PHE}$ groups, when respectively compared to the concentration recorded in the control group. Potassium ion concentrations obtained in between the treatment groups did not differ $(\mathrm{P}>$ 0.05 ) (Figure 1.0).

\section{Effect of Treatment on Chloride ion Concentration}

There was no significant $(\mathrm{P}>0.05)$ change in $\mathrm{Cl}^{-}$concentration in between the groups. The changes in the mean $\mathrm{Cl}^{-}$concentration in the $\mathrm{PHE}$ and $\mathrm{CBZ}+\mathrm{PHE}$ groups were not different, when compared to that of the CBZ group (Figure 1.0)

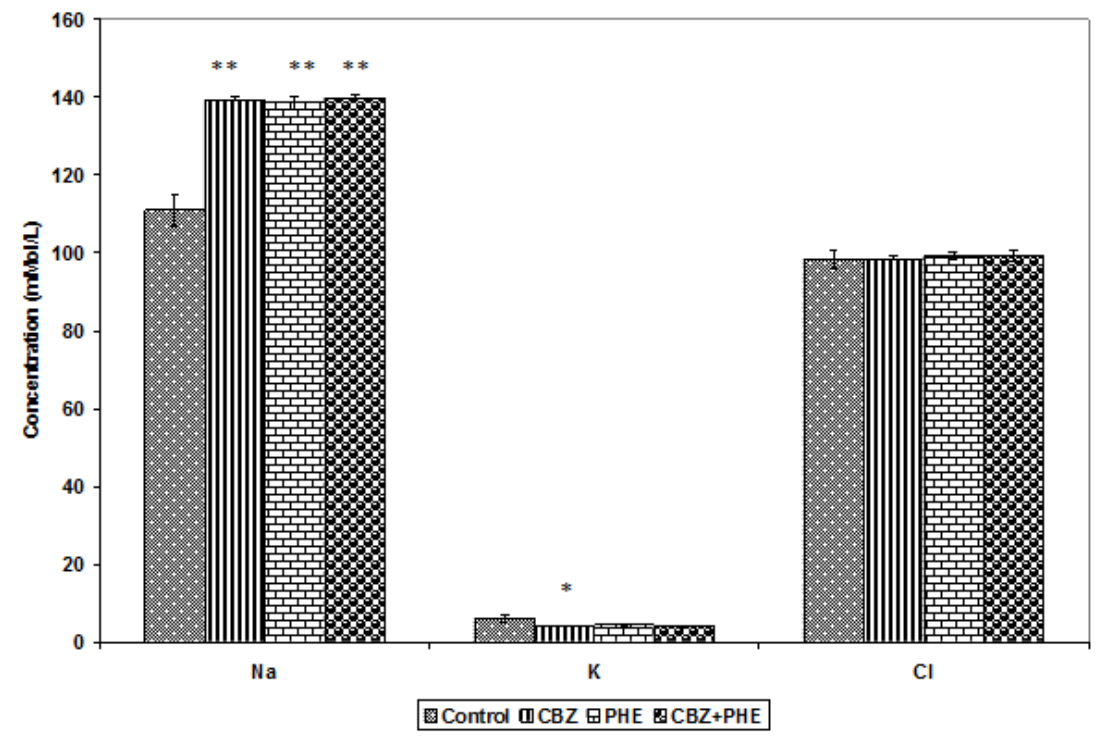

Figure 1.0: Effect of administration of carbamazepine (CBZ), and/or phenytoin (PHE) on serum electrolyte concentrations in Wistar rats $(n=10)$

$\mathrm{Na}=$ Sodium ion

$\mathrm{K}=$ Potassium ion

$\mathrm{Cl}=$ Chloride ion

$*=\mathrm{P}<0.05$ (CBZ, CBZ+PHE Vs Control)

$* *=\mathrm{P}<0.0001(\mathrm{CBZ}, \mathrm{PHE}, \mathrm{CBZ}+\mathrm{PHE}$ Vs Control)

\section{Effect of Treatments on Serum Proteins in Wistar Rats}

\section{Effect of Treatments on Serum Total Proteins}

There were no significant $(\mathrm{P}>0.05)$ changes in the concentrations of total proteins, obtained in between the drug-treated groups, and when the concentration in each of the treatment groups was compared to that of the control group (Figure 1.1)

\section{Effect of Treatments on Serum Albumin Concentration}

Albumin concentrations in the CBZ, PHE and CBZ+PHE groups were higher $(\mathrm{P}<0.01)$, when respectively compared to that of the control group. There were no significant $(\mathrm{P}>0.05)$ changes in albumin concentrations recorded between the drug-treated groups (Figure 1.1).

\section{Effect of Treatments on Globulin Concentration}

Globulin concentration decreased significantly $(\mathrm{P}<0.05)$ in the CBZ and PHE groups, when respectively compared to that of the control group. There was no significant $(\mathrm{P}>0.05)$ change in globulin concentration in the $\mathrm{CBZ}+\mathrm{PHE}$ group, when compared to that of the control group. Globulin concentrations in between the drug treatment groups were not different $(\mathrm{P}>0.05)$ (Figure 1.1). 


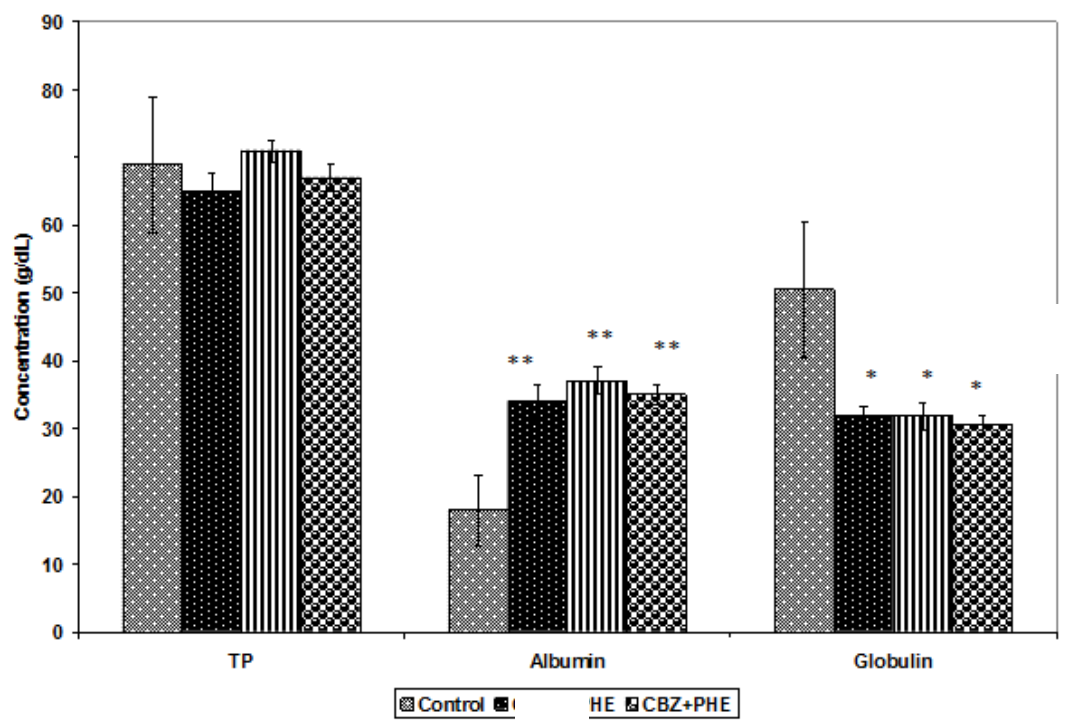

Figure 1.1: Effect of administration of carbamaze _... CBZ) and/or phenytoin (PHE) on serum proteins in Wistar rats $(\mathrm{n}=10)$

$\mathrm{TP}=$ Serum Total proteins

$*=\mathrm{P}<0.05(\mathrm{CBZ}, \mathrm{PHE}, \mathrm{CBZ}+\mathrm{PHE}$ Vs Control)

$* *=\mathrm{P}<0.01(\mathrm{CBZ}, \mathrm{PHE}, \mathrm{CBZ}+\mathrm{PHE}$ Vs Control)

\section{Effect of Treatments on Serum Urea Concentration}

Urea concentration in CBZ and PHE groups was lower $(\mathrm{P}<0.05)$ when compared to the value recorded in the control group. There was no change in urea concentrations obtained between the antiepileptic drug-treatment groups (Figure 1.2).

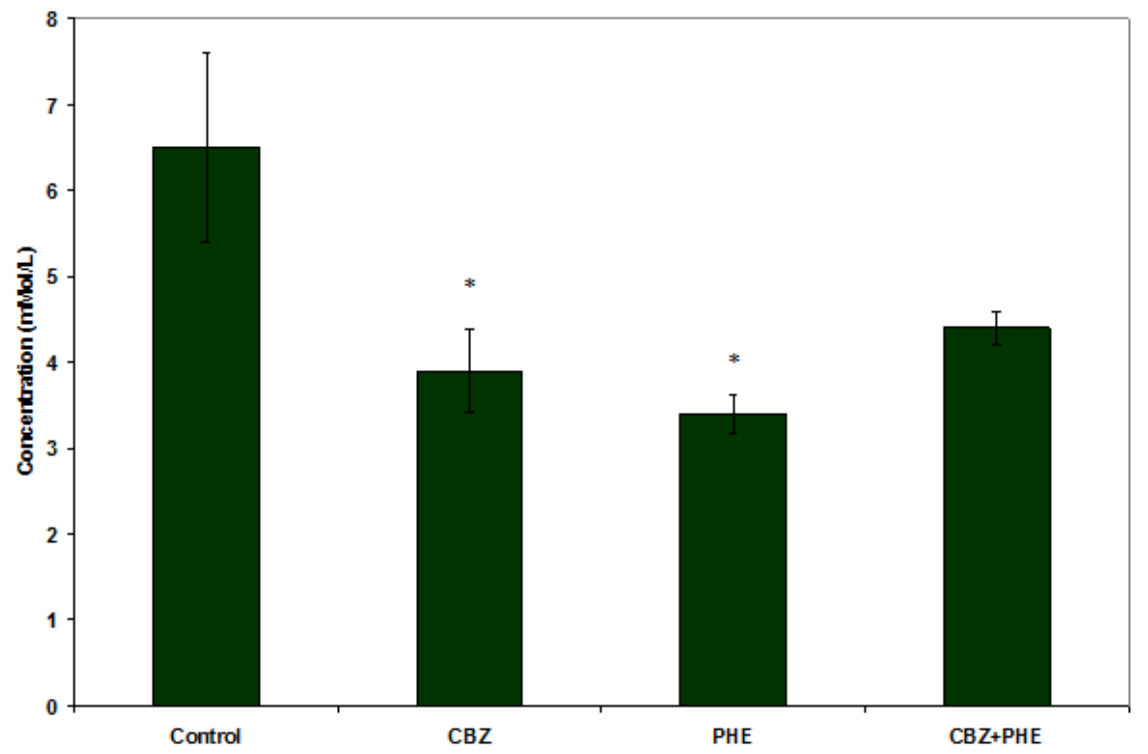

Figure 1.2: Effect of administration of carbamazepine (CBZ) and/or phenytoin (PHE) on urea concentration in Wistar rats $(n=10)$ $*=\mathrm{P}<0.05(\mathrm{CBZ}, \mathrm{PHE}$ Vs Control)

\section{Effect of Treatments on Liver Enzyme Activities}

\section{Effect of Treatments on Alanine Aminotransferase}

The ALT activity in the CBZ and CBZ+PHE groups rose significantly $(\mathrm{P}<0.05)$, when compared to that of the control group. The ALT activities in the PHE group and that of the control were not significant. There were also no significant $(\mathrm{P}>0.05)$ changes in ALT activities between the drug-treated groups (Figure 1.3). 


\section{Effects of Treatments on Aspartate Aminotransferase}

A significant $(\mathrm{P}<0.05)$ increase in AST activities was recorded in the PHE group, when compared to that of the control group. Increases in AST activity in the CBZ and CBZ+PHE groups were not significantly $(\mathrm{P}>0.05)$ different, also, no significant $(\mathrm{P}>0.05)$ change in AST activity, when the treatment groups were compared (Figure 1.3).

\section{Effect of Treatments on Alkaline Phosphatase Activity}

Changes in ALP activity in the CBZ, PHE and CBZ+PHE groups, when respectively compared to that of the control group were insignificant $(\mathrm{P}>0.05)$. The increase in ALP activity in the PHE group, when compared to that of the CBZ or CBZ+PHE group was insignificant. Similarly an insignificant increase was recorded in the CBZ+PHE group when compared to that of the CBZ group (Figure 1.3).

\section{Effect of Treatments on Lactate Dehydrogenase Activity}

There were no significant $(\mathrm{P}>0.05)$ changes in LDH activity in the CBZ, PHE and CBZ+PHE groups, when respectively compared to that of the control group. There was a relative, but insignificant $(P>0.05)$, decrease in LDH activity in the CBZ group, compared to either that of the PHE or CBZ+PHE group. Although the LDH activity in the PHE group increased over that recorded in the CBZ+PHE group, the difference in the activities was not significant (Figure 1.3).

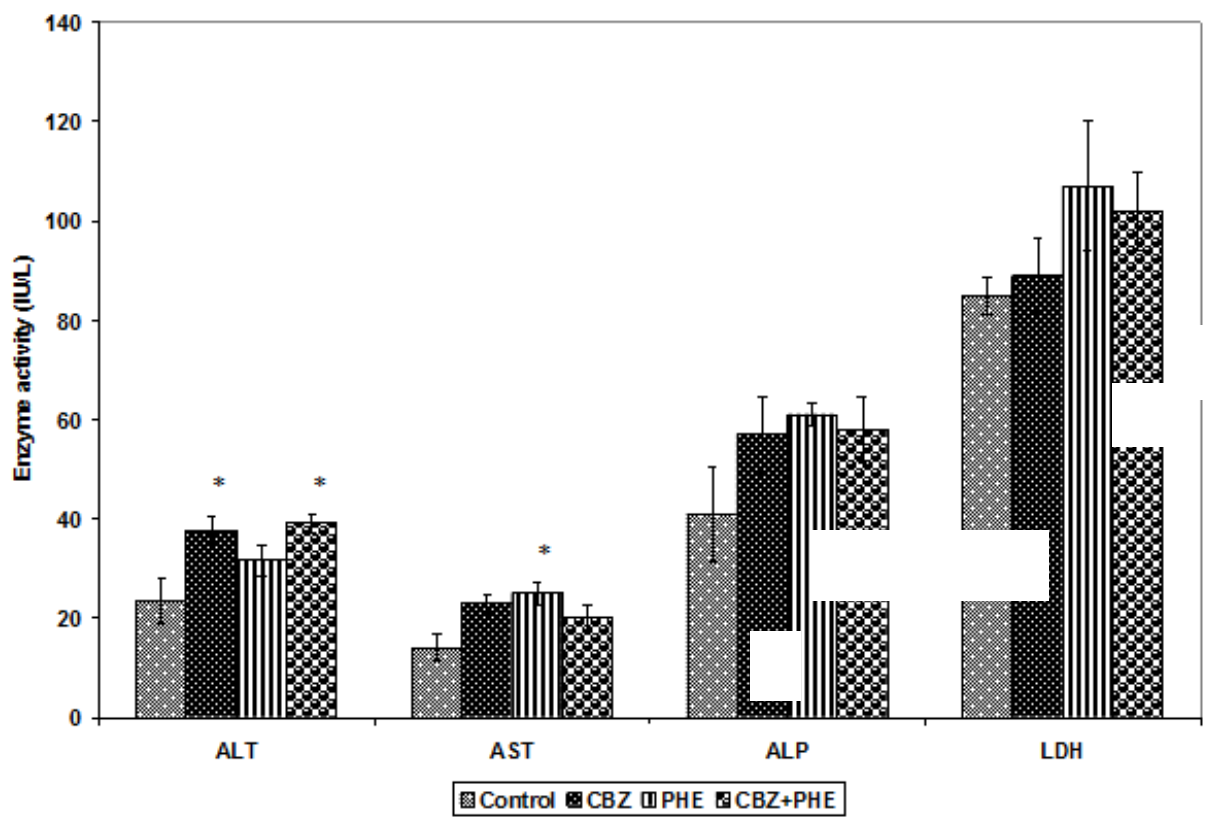

Figure 1.3: Effect of administration - arbamazepine (CBZ) and/or phenytoin (PHE) on serum liver

ALT $=$ Alanine aminotransferase

enzyr ctivities in Wistar rats $(n=10)$

AST $=$ Aspartate aminotransferase

ALP $=$ Alkaline phosphatase

$\mathrm{LDH}=$ Lactate dehydrogenase

$*=\mathrm{P}<0.05(\mathrm{ALT}=\mathrm{CBZ}, \mathrm{CBZ}+\mathrm{PHE}$ Vs Control; $\mathrm{AST}=\mathrm{PHE}$ Vs Control $)$

\section{Discussion}

The increase in $\mathrm{Na}^{+}$concentration in the antiepileptic drug (AED)-treated groups agrees with the findings of [19] that demonstrated an increase in $\mathrm{Na}^{+}$; but disagrees with that of [11], who reported hyponatraemia following the administration of $\mathrm{CBZ}$ and oxcarbamazepine. The result of the present study also disagrees with that of [23], who obtained hyponatraemia following CBZ administration. According to [13], PHE exerts a transient inhibitory effect on ADH release by the posterior pituitary gland, and it increases water reabsorption in the collecting duct of the kidneys, PHE has also been shown to reverse the hyponatraemia induced by CBZ therapy. The reason for the decrease in $\mathrm{K}^{+}$concentration in the CBZ-treated group is not known. However, hypokalaemia may be observed with increased activity of the adrenal cortex, and this may cause the body to reclaim $\mathrm{Na}^{+}$from the urine in exchange for $\mathrm{K}^{+}$excretion. Thus, high $\mathrm{Na}^{+}$concentration was obtained in the present study with relative decrease in serum $\mathrm{K}^{+}$for the $\mathrm{CBZ}$ group. 
The increase in albumin concentration observed in the present study may be as a result of overproduction of cortisol by the adrenal glands [10]. According to [28], the arene oxide metabolites of PHE and CBZ may cause oxidative stress. PHE group had the greatest increase in serum albumin, indicating pronounced increase in cortisol production. The decrease in globulin concentration in the AED-treated groups agrees with the results of [4] who showed that CBZ therapy caused decrease in $\operatorname{IgA}$ and $\mathrm{IgG}$ levels. PHE was also reported to cause an induction of transient selective IgA deficiency. Rats co-administered with CBZ and PHE had the greatest decrease in globulin concentration, indicating higher decrease in immunoglobulins $\mathrm{A}$ and $\mathrm{G}$. This finding may be due to the synergistic effects of the drugs. The decrease in urea concentration in the AED-treated groups may be due to impaired protein metabolism, apparently, due to hepatic dysfunction. This is because the liver converts proteins into urea for excretion. This impairment may be due to persistent assault on the liver by the drugs or their metabolites, since the liver is the site of metabolism and detoxification of the drugs. The metabolism of these AEDs results in the formation of toxic epoxides from the action of cytochrome $\mathrm{P}_{450 \mathrm{~s}}$, resulting in hepatic dysfunction [25].

There was an increase in ALT activity in the CBZ and CBZ+PHE-treated groups. This finding disagrees with the report of [15], who observed moderate elevation of ALT activity with PHE therapy. These changes were transient and may be due in part to induced synthesis of the enzymes. Transient elevation of ALT activity with CBZ therapy may be due to hepatocellular damage [7]. The highest ALT activity obtained in the group co-administered with CBZ and PHE demonstrated greater hepatocellular injury than in the CBZ group. AST activity was found to be the highest in the PHE-treated group control. This finding indicates that PHE may cause more damage to the organs (liver, cardiac and skeletal muscles, kidneys, brain and blood cells), where the enzyme is found. [2]; showed that increases in AST, ALT and ALP activities are more frequent and higher with diphenylhydantoin than with CBZ. Except in the case of ALT activity, which was higher in the CBZ group, the AST and ALP (although, insignificant) activities were highest by $40.7 \%$ and $35 \%$, respectively in the PHE group in the present study. [7], also reported increased activities of ALT, AST and ALP with long-term PHE therapy in rats, attributed to hepatocellular damage. Phenytoin, phenobarbital and carbamazepine have been shown to be highly toxic to the skin, liver, brain, kidneys and gastro-intestinal tract [16]. The predisposition to the toxic effects of PHE and CBZ is presumed to be a consequence of an inherited deficiency in the detoxifying enzyme(s) epoxides hydrolase [22].

\section{Conclusion}

In conclusion, administration of CBZ and/or PHE induced significant alterations in serum biochemical parameters in Wistar rats, which, in most cases may be transient, and can reverse when the drugs are discontinued. It is, however, recommended that serum biochemical parameters should be strictly monitored and regularly evaluated in individuals treated with CBZ and/or PHE.

\section{REFRENCES}

[1]. Abbondazo SL, Ivey NS and Frizzera G. Dilantin associated lymphadenopathy: Spectrum of histopathologic patterns. Ame J Surg Path, 1995; 19: 675-686.

[2]. Aldenhövel HG. The influence of long-term anticonvulsant therapy with diphenylhydantoin and carbamazepine on serum on aspartate aminotransferase, alanine aminotransferase and alkaline phosphatase. E Arch Psych and Neurol Sci, 1988; 237(5): 312-316.

[3]. Almgrem M, Nyengaard JR, Persson B and Lavebralt C. Carbamazepine protects against neuronal hyperplasia and abnormal gene expression in the megencephaly mouse. Neurobiol Dis, 2008; 32: 364-376.

[4]. Ashrafi M, Hosseini SA, Abolmaali S, Biglari M, Azizi R, Farghadan M, Samadian A, Shaghafi S, Mombeini H, Saladjegheh N, Rezaei N and Aghamohammadi A. Effect of anti-epileptic drugs on serum immunoglobulin levels in children. Acta Neurol Belgica, 2010; 110: 65-70.

[5]. Bryan CH and Waxman SG. Neuroprotection by sodium channel blockade with phenytoin in an experimental model of glaucoma. Investig Ophthal and Visual Sci, 2005; 46(11): 4164-4169.

[6]. DeVriese AS, Philippe J and Van Reuterghem DM. Carbamazepine hypersensitivity syndrome: report of 4 cases and review of the literature. Medicine, (Baltimore), 1995; 74: 144-151.

[7]. Ekaidem IS, Akpanabiatu MI, Uboh FE. and Eka OU. Vitamin B 12 supplementation: effects on some biochemical and haematological indices of rats on phenytoin administration. Biokemistri, 2006; 18(1): 31-37.

[8]. Fern R, Ransom BR, Stys PK and Waxman SG. Pharmacologic protection of CNS white matter during anoxia: Actions of phenytoin, carbamazepine and diazepam. J Pharm Expe Ther, 1993; 266: 1549-1555.

[9]. Hoshino C and Hoshi T. Carbamazepine-induced agammaglobulinaemia clinically mimicking diffuse panbrochioloitis. B Med J Reports, 2011; doi:10.1136/bcr.11.2010.3535

[10]. Kaslow J. Proteins-albumin, globulins. 2011. Cited April, 2012. Available from http://www.drkaslow.com/html/proteins-albuminglobulins-html

[11]. Kolb SJ. and Litt B. Management of epilepsy and comorbid disorders in the emergency room and intensive care unit. In: Ettinger, A. B. and Devinsky, O. (Eds.). Managing Epilepsy and Co-existing Disorders. Boston. Butterworth-Heinemann, 2002; Pp. 515535 .

[12]. Kšerk P, Haugvicovă P and Mareš P. Age-dependent phenytoin effects oncortical stimulation in rats. Physiol Res, 1998; 47: 143149.

[13]. Liamis G, Milionis HJ. and Elisaf M. A review of drug-induced hypernatraemia. Clin Kidney J, 2009; 2(5): 339-346. 
[14]. Macdonald, RL and Meldrum, BS. Principles of antiepileptic drug action. In: Mattson RH and Meldrum BS. (Eds.) Antiepileptic Drugs, $4^{\text {th }}$ Ed, Pp. 61-78, Raven Press, New York, 1995.

[15]. McNamara JO (ed.), Pharmacotherapy of epilepsy. In: Goodman and Gilman's The Pharmacological Basis of Therapeutics, $11^{\text {th }}$ Ed, Pp. 501-525, New York: McGraw-Hill, 2006.

[16]. Misra U K, Kalita J and Rathore C. Adverse drug reaction: phenytoin and carbamazepine cross reactivity: report of a case and review of literature. Postgraduate Med J, 2003; 79: 703-704.

[17]. Nair DR Epilepsy. Cleveland Clinic Foundation. 2003. Cited Feb $28 \quad 2008 . \quad$ Available from: http://wwww.clvelandclinicmeded.com/medicalpubs/diseasemanagement/neuroly/epileptic-syndrome. Accessed on 28/2/2008.

[18]. Parks-Veal PM. Novel uses of antiepileptic drugs. 2000, Cited Feb 28 2008. Available from: http://www.ascp.com/publications/tcp/2000/mar/forum.shtml.

[19]. Porter RJ and Meldrum BS. Antiseizure drugs. In: Basic and Clinical Pharmacology, 10 ${ }^{\text {th }}$ Ed, Pp. 374-394, New York, McGrawHill, 2007.

[20]. Rajesh KR, Surendra R and Thangam J. Effect of valproic acid and carbamazepine on learning and memory in rats. Ind J Pharmacol,1991; 23(30: 185-188.

[21]. Rang HP, Dale MM, Ritter JM and Flower RJ. Mechanism of action on antiepileptic drugs. In: Rang and Dale Pharmacology, $6^{\text {th }}$ Ed, Pp 578-584, Churchhill Livingstone, 2007.

[22]. Riley RJ, Kitteringham NR and Park BK. Structural requirements for bioactivation of anticonvulsants to cytotoxic metabolites in vitro. B J Clin Pharmacol, 1989; 28: 482-487.

[23]. Salawu F and Danburam A. Hyponatraemia during low-dose carbamazepine therapy. Ann of Afri Med, 2007; 6(4): 207-208.

[24]. Schmidt D. Efficacy of new antiepileptic drugs. Epi Cur, 2011; 11(1): 9-11.

[25]. Spielberg SP. In vitro analysis of idiosyncratic drug reactions. Clin Bioch, 1986; 19: 142-144.

[26]. Sun, M, Van Rijn CM, Liu Y and Wang M. Combination of carbamazepine and valproate in different dose proportion in maximal electroshock seizure model in mice. Epi Res, 2002; 51(1-2): 5-11.

[27]. Swann AC. Major system toxicities and side-effects of anticonvulsants. J Clin Psychiatry, 2001; 62 s14: 16-21.

[28]. Thakur S, Saraswathy GR and Maheswari E. Influence of vitamin C on phenytoin induced haematotoxicity and oxidative stress in rats. Inter J Pharmac Res and Inno, 2011; 2: 32-39.

[29]. Vijay P, Yeshwanth R and Bairy KL. Effect of phenytoin sodium on biochemical Parameters of reproductive function in male albino Wistar rats. J Physiol and Biomed Sci, 2002; 22(2): 14-18. 